\title{
Fludarabine, Cytarabine and Gentuzumab Ozogamicin (FLA-GO) as Salvage Therapy and Bridge to Transplant in Adult Relapsed Acute Myeloid Leukemia (AML) Patients
}

Cefalo $\mathrm{M}^{1}$, Del Principe MI ${ }^{1}$, Buccisano $\mathrm{F}^{1}$, Di Piazza F ${ }^{1}$, Ottaviani $L^{1}$, Maurillo $L^{1}$, Sarlo $C^{2}$, De Santis G', Consalvo $\mathrm{MI}^{1}$, De Bellis $\mathrm{E}^{\mathbf{1}}$, De Angelis $G^{1}$, Zizzari $A^{1}$, Paterno G ${ }^{1}$, Divona $M^{1}$, Postorino M$^{1}$, Del Poeta G ${ }^{1}$, Sconocchia G ${ }^{3}$, Arcese W' Amadori $\mathbf{S}^{\mathbf{1}}$ and Venditti $\mathrm{A}^{\mathbf{1}}$

${ }^{1}$ Cattedra di Ematologia, Dipartimento di Biomedicina e Prevenzione, Università Degli Studi di Roma “Tor Vergata", Italy

${ }^{2}$ Ematologia, Policlinico Universitario-Campus

Biomedico, Italy

${ }^{3}$ Istituto di Farmacologia Translazionale, Dipartimento di Medicina, CNR, Italy

*Corresponding author: Maria Ilaria Del Principe, Cattedra di Ematologia, Dipartimento di Biomedicina e Prevenzione, Università Degli Studi di Roma "Tor Vergata", Roma, Italy

Received: J anuary 25, 2017; Accepted: March 16, 2017; Published: March 31, 2017

\section{Introduction}

Prognosis of adult patients with relapsed/refractory acute myeloid leukemia (AML) is generally unsatisfactory with a 5-year overall survival (OS) of $10-30 \%$ [1-4]. Such a dismal outcome is well explained with a lack in availability of effective salvage options and with the problematic access to allogeneic stem cell transplantation (ASCT), which remains the only potential curative approach.

Salvage regimens generally rely on the delivery of high-dose cytarabine (ARA-C), alone or in combination, followed by ASCT [5]. Among combinatorial approaches, the association of fludarabine and ARA-C (FLA) was found to be superior to ARA-C single agent. In fact, fludarabine modulates the pharmacologic activation of ARA-C [6-8] therefore increasing the rate of accumulation of its active metabolite ARA-C 5'-triphosphate [6].

Besides attempts to ameliorate the efficacy of conventional chemotherapy, developing and implementing programs of "targeted therapy" has represented a further expedient to approach difficultto-treat diseases such as relapsed/refractory AML. Among agents able to target specific leukemic antigens or pathways, Gentuzumab Ozogamicin (GO) is one of the most extensively investigated. GO is a humanized anti-CD33 monoclonal antibody conjugated to a semisynthetic derivative of calicheamicin, a cytotoxic drug that is released inside the leukemic cells after the internalization of the immunoconjugate. $\mathrm{CD} 33$ is a $67-\mathrm{kD}$ transmembrane cell surface glycoprotein receptor, which represents an attractive target for immunotherapy since it is expressed on the external surface of leukemic blasts in more than $80 \%$ of patients with AML, but not on normal precursor hematopoietic cells [4]. Either as a single agent or in combination with chemotherapy, GO was reported to improve overall responses rate in adults with relapsed/refractory AMLs [8-10].

Based on these premises, we conducted a retrospective analysis of 27 adult patients with relapsed/refractory AML, to evaluate the efficacy and the safety of the association FLA plus GO (FLA-GO) and to assess the feasibility of ASCT after FLA-GO.

\section{Patients and Methods}

\section{Patients}

Twenty-seven adult patients with refractory/relapsed AML treated with FLA-GO regimen between 2006 and 2010 at the Policlinico Tor Vergata of Rome, were analyzed for the purposes of the present study. Approval for this study was obtained from the institutional review board. All patients received written informed consent in accordance with the declaration of Helsinki. Inclusion criteria were relapsed/ refractory AML, age $>18$ years, ECOG performance status $\leq 2$ [11], normal renal and liver function (creatinine $\leq 2 \mathrm{mg} / \mathrm{dl}$, total bilirubin $\leq 2 \mathrm{mg} / \mathrm{dl}$ ), adequate cardiac function (LVFE $\geq 50 \%$ ). Patients with Acute Promyelocitic Leukemia were excluded.

\section{Routine molecular, karyotypic and immunophenotypic analysis}

Total RNA was extracted from Ficoll-Hypaque isolated bone marrow mononuclear cells collected both at diagnosis and at disease
Ann Hematol Oncol - Volume 4 Issue 4 - 2017 ISSN : 2375-7965 | www.austinpublishing group.com Del Principe et al. (C) All rights are reserved
Citation: Cefalo M, Del Principe MI, Buccisano F, Di Piazza F, Ottaviani L, Maurillo L, et al. Fludarabine, Cytarabine and Gentuzumab Ozogamicin (FLA-GO) as Salvage Therapy and Bridge to Transplant in Adult Relapsed Acute Myeloid Leukemia (AML) Patients. Ann Hematol Oncol. 2017; 4(4): 1145. 
relapse using standard procedures [12] and reverse-transcribed with random hexamers as primers [13]. Diagnostic molecular studies for recurrent translocations were performed according to previously published methods [13]. DNA was also extracted using a columnbased Qiagen kit protocol. Fms-like tyrosine kinase- internal tandem duplication (FLT3 ITD) and nucleophosmin 1 (NPM1) gene mutations were investigated using protocols reported elsewhere [1417].

Conventional karyotyping was performed on bone marrow aspirates after short-term culture and analysed after G-banding. The description of the karyotype was according to the International System for Human Cytogenetic Nomenclature [18].

Bone marrow samples were also collected for immunophenotyping with a standard panel of antibodies [19]. Briefly, each antibody was incubated with $1-2 \times 10^{6}$ cells in a $100 \mu$ of volume, and isotypematched antibodies were used as negative controls. After incubation, cells were re-suspended in $0.5 \mathrm{ml}$ PBS and analyzed with a flow cytometer (Facs Canto; Becton Dickinson). Percentage of CD33 positive blasts was determined drawing a proper gate on the leukemic population in the FSC/SSC plot.

\section{Treatment schedule}

The chemotherapy regimen consisted in a 30 -minute infusion of intravenous fludarabine, $30 \mathrm{mg} / \mathrm{m}^{2} /$ day on days $1-5$ and, on the same days, in 2-hour infusion of intravenous ARA-C, $2 \mathrm{~g} / \mathrm{m}^{2} /$ day. In order to generate the best pharmacologic interaction between fludarabine and ARA-C, infusion of ARA-C began 4 hours after the end of that of fludarabine. On day 6, intravenous GO (Mylotarg, Pfizer, New York, NY, and Ben Venue Laboratories, Bedford, OH, USA) was infused at the dose of $6 \mathrm{mg} / \mathrm{m}^{2}$ Thirty minutes before GO administration, all patients received a pre-medication with methylprednisolone $(40 \mathrm{mg}$, flat dose ). Duration of GO infusion was two hours. All patients had a central venous catheter (CVC) inserted, all received fluoroquinolonebased and anti-fungal prophylaxis from the start of chemotherapy until resolution of neutropenia or introduction of empirical antibiotic therapy for febrile neutropenia. When transfusions were required, blood components were irradiated before infusion [20].

\section{Response definition and safety monitoring}

Bone marrow aspiration for determination of response was performed on day $+28 \pm 2$ from the start of chemotherapy. Response criteria were those of the International Working Group [21] based on whichCR was defined as a bone marrow blasts count $<5 \%$, absolute neutrophil count $>1 \times 10^{9} / 1$, platelets count $>100 \times 10^{9} / 1$ and transfusions independence. Partial Remission (PR) was defined as a bone marrow blasts percentage of $5 \%$ to $25 \%$. Toxicity was evaluated according to Common Terminology Criteria for Adverse Events [22]. Early death (ED) was defined as death within 31 days following day 1 of chemotherapy administration.

\section{Outcome definition and statistical analysis}

Descriptive statistics are presented including median and range for continuous variables, absolute and relative frequencies for categorical variables. The relapse rate after FLA-GO was assessed by the cumulative incidence (CI) function, using the competing risks method and considering death without relapse like competing event. The Kaplan-Meier product-limit method was used to estimate and
Table 1: Patient's characteristic.

\begin{tabular}{|c|c|}
\hline PatientsCharacteristic & $n(\%)$ \\
\hline Total patients & 27 \\
\hline \multicolumn{2}{|l|}{ Gender } \\
\hline Male & $20(74 \%)$ \\
\hline Female & $7(26 \%)$ \\
\hline Age, medianyears & 58 \\
\hline Range & $22-71$ \\
\hline$\geq 60$ years & $12(44 \%)$ \\
\hline$<60$ years & $15(56 \%)$ \\
\hline \multicolumn{2}{|l|}{ PS ECOG } \\
\hline 0 & $8(30 \%)$ \\
\hline 1 & $16(59 \%)$ \\
\hline 2 & $3(11 \%)$ \\
\hline \multicolumn{2}{|l|}{ WBC count } \\
\hline$\geq 50 \times 10^{3} / \mathrm{L}$ & $6(22 \%)$ \\
\hline$<50 \times 103 / L$ & $21(78 \%)$ \\
\hline \multicolumn{2}{|l|}{ Diseasephase } \\
\hline Relapsed & $22(81 \%)$ \\
\hline Refractory & $5(19 \%)$ \\
\hline \multicolumn{2}{|l|}{ Cytogeneticriskgroups } \\
\hline Good & $2(8 \%)$ \\
\hline Intermediate & $15(55 \%)$ \\
\hline Poor & $8(29 \%)$ \\
\hline Unknown & $2(8 \%)$ \\
\hline \multicolumn{2}{|l|}{ CD33 expression } \\
\hline$\geq 80 \%$ & 19(70\%) \\
\hline$<80 \%$ & $8(30 \%)$ \\
\hline \multicolumn{2}{|l|}{ NPM1 } \\
\hline Positive & $3(11 \%)$ \\
\hline Negative & $16(60 \%)$ \\
\hline Unknown & $8(29 \%)$ \\
\hline \multicolumn{2}{|l|}{ FLT3 } \\
\hline Positive & $8(30 \%)$ \\
\hline Negative & $8(30 \%)$ \\
\hline Unknown & $11(40 \%)$ \\
\hline \multicolumn{2}{|l|}{ Blastcount } \\
\hline$>50 \%$ & $15(58 \%)$ \\
\hline$<50 \%$ & $11(42 \%)$ \\
\hline
\end{tabular}

plot the OS. Differences between groups were determined using the Gray's test and the log-rank test for the CI measures and for OS, respectively. A p value of $<0.05$ was considered statistically significant. All the analysis were conducted using software R version 2.15.0.

\section{Results}

The clinical and biological characteristics of the 27 patients are summarized in Table 1. Twenty patients were males, 7 females. Median age was 58 years (range 22-71 years). Five patients had 


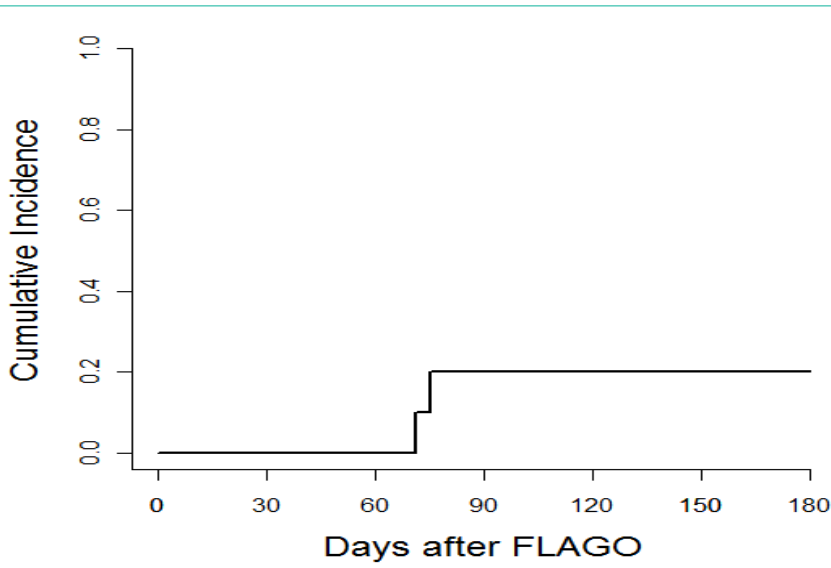

Figure 1: Cumulative Incidence of Relapse after FLAGO $20 \pm 13 \%$.

an AML primarily refractory to a first induction course and 22 were in first relapse after a frontline induction regimen combining anthracycline, etoposide and ARA-C. Among patients in first relapse, 2 relapsed after ASCT and 1 after autologous SCT. In 14 of 22 (64\%) patients who relapsed, duration of first CR (CR1) was $\geq 12$ months. Overall, median duration of CR1 was 9 months (range 2-110). At the time of resistance or relapse, cytogenetic data were available in 25 of 27 (93\%) patients: $2(8 \%), 15(55 \%)$ and $8(29 \%)$ had a favorable-, intermediate- and unfavorable-risk karyotype, respectively [23] From a molecular point of view, 8 of the 27 (30\%) patients had FLT3 ITD mutation and $3(11 \%)$ had both NPM1 and FLT3-ITD mutation. Median percentage of CD33 expression was $88 \%$ (range 4-100\%) with 19 patients $(70 \%)$ showing positivity in more than $80 \%$ of the leukemic blasts.

The overall CR rate after 1 course of FLA-GO was $37 \%$ (10/27 patients). The median time to CR was 36 days (range 25-49) with no PR being observed. None of the patients affected by primary refractory AML achieved a CR after FLA-GO. Patients younger $<60$ years and with CR1 duration $>12$ months achieved CR more frequently than those of age $>60$ years $(70 \% v s .30 \%$, $\mathrm{p}=\mathrm{ns})$ or with CR1 $<12$ months (( $70 \%$ vs $30 \%, p=n s)$. No difference in CR rate was observed according to CD33 expression or cytogenetic pattern. Six out of 10 patients (60\%) (median age 55, range 27-63) who achieved a CR2 were successfully addressed to ASCT, with none of them receivingpre-emptive or prophylactic donor lymphocyte infusion. With a median follow-up of 5.3 years, the6-months cumulative
Table 2: Side effects.

\begin{tabular}{|l|c|}
\hline Adverse events & Patients n(\%) \\
\hline Febrile neutropenia & $\mathbf{2 7}$ \\
\hline Grade III & $21(78 \%)$ \\
\hline Grade V & $1(3.7 \%)$ \\
\hline Pneumonitis & 10 \\
\hline Grade II & $7(26 \%)$ \\
\hline Grade III & $3(11 \%)$ \\
\hline Mucositis & $\mathbf{6}$ \\
\hline Grade III & $6(22 \%)$ \\
\hline Livertoxicity & $\mathbf{2}$ \\
\hline Grade II & $2(7 \%)$ \\
\hline Thrombosis Central venouscatheter & $\mathbf{2}$ \\
\hline Grade II & $2(7 \%)$ \\
\hline Bleeding & $\mathbf{6}$ \\
\hline Grade II & $3(11 \%)$ \\
\hline Grade IV & $3(11 \%)$ \\
\hline
\end{tabular}

incidence of relapse (CIR) and 2-yearsOS was $20 \pm 13 \%$ (Figure 1) and $20 \pm 8 \%$ (Figure 2), respectively.

All patients experienced grade 3-4 chemotherapy-related hematological toxicities. The median duration of neutropenia and thrombocytopenia was 27 (range 11-33) and 25 days (range 9-30), respectively. Febrile neutropenia was observed in $78 \%$ of the patients whereas infectious episodes (pneumonia)in 37\% [22]. One case of febrile neutropenia was fatal (grade 5) $(\mathrm{ED}=3.7 \%)$. Grade 3 mucositis was observed in 6 patients (22\%) and in $2(7 \%)$ a mild and transient liver toxicity. No infusion related symptoms or sinusoidal obstructive syndrome (SOS) due to GO administration was reported (Table 2), even in patients who received to ASCT.

\section{Discussion}

We evaluated the efficacy and safety of a combined immunechemotherapy regimen associating fludarabine, ARA-C and GO, in a group of patients affected by relapsed or primary refractory AML. Therapy was well tolerated and CR was reported in $37 \%$ of those with relapsed AML. This figure is in line with other purine nucleoside analog-based regimens such as FLA (36\%) [7], FLAG-
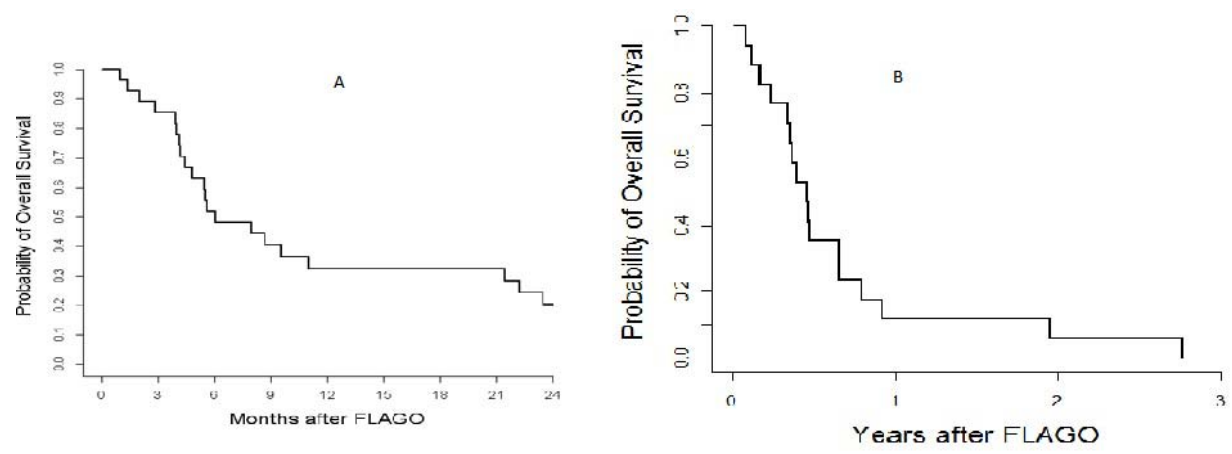

Figure 2: Kaplan-Mejer estimate of Overall Survival (OS) of responders patients (A) and of non-responders patients (B). 
IM (fludarabine, ARA-C, idarubicin, GO) (39\%) [24] or clofarabine (32\%) [25]. In a recent report, the CR rate of 259 patients treated with FLA-idarubicin or FLAGO-idarubicin was $51 \%$. Therefore in large series, it appears that the addition of an anthracycline may increase the effectiveness of GO [26].

No patients with primary refractory AML achieved response after FLA-GO regimen. Probably, this very high risk group of patients would benefit from the use of GO within anthracycline-based regimens or newer therapies.

A successful outcome after salvage therapy depends on duration of first CR, cytogenetics at diagnosis and previous history of ASCT [8-9,25-27]. Although the difference was not statistically significant, likely due to the small sample size, we observed that patients younger than 60 years and those with CR1 duration $\geq 12$ months had a higher response rate.

As regard to the impact of genetics/cytogenetics on response rate, we were not able to appreciate any significant difference between the risk-categories, likely due to the small sample size. Furthermore, only one instance of favorable karyotype was detected with the majority of subjects belonging to the intermediate- or unfavorable-risk category.

Preclinical data indicate that GO is more effective in AMLs with a high CD33 expression [28]. In a study of GO single-agent for unfit elderly patients with previously untreated AML, Amadori et al. confirmed this observation [29]. In our study no association between CD33 expression and clinical outcome emerged, this is in line with others' experience in which GO wasnot delivered as single agent but rather given in association with chemotherapy [30,3 1].

We reported a manageable hematologic toxicity, comparable to that commonly described in the setting of salvage therapy $[7,32]$ and inferior to the one observed in the recent series of 259 patients treated with GO in the context of an anthracycline-based regimen [26]. Even liver toxicity was negligible and no instances of SOS were observed in the overall population and in patients submitted to ASCT [31,33-36]. Overall, ED rate was in line or even lower than what observed in other chemotherapy trials $[8,25]$. The optimal schedule of GO administration remains uncertain [37]. In most clinical trials the first dose of GO was administered on day 1 together with chemotherapy $[31,38]$. Others opted for a delayed administration so that GO was infused on the last day of chemotherapy $[24,32,37,39]$. The combination of methylprednisolone pre-medication and delayed GO infusion might explain why no serious infusion related adverse events were observed. Additionally, the delayed GO infusion might be particularly indicated in patients with high WBCc. In fact, the fall in the number of WBC induced by chemotherapy may prevent either a GO-induced tumor lysis syndrome or the so called "sinkeffect" due to the peripheral blast absorption of anti-CD33 [37]. Relapsed/refractory AML is a fatal condition that cannot be cured by therapy other than ASCT [40]. However, less than 30-40\% of the candidates has eventually access to the procedure because of the very short duration of CR2, the prolonged cytopenia and, more in general, because of the toxicity caused by the multiple exposures to chemotherapy $[41,42]$. In our series, $60 \%$ of the patients achieved a CR2 that was stable enough to allow an ASCT to be performed. This results are in line with other studies [32,38] and similar to those of clofarabine containing protocols.

Although based on a small sample size, our results suggest that this combination can generate promising response rates in a population of very high-risk AML patients, younger than 60 years and with a CR1 duration $\geq 12$ months, without relevant therapyrelated toxicities. Further studies are needed to confirm our results and to better define the subsets of patients who may benefit from this combinatorial therapy. The FLA-GO regimen may also represent an advantageous preparatory salvage for candidates to receive ASCT as a post-CR2 consolidation, mainly for its favorable toxicity profile.

\section{References}

1. Ravandi F. New treatments and strategies in acute myeloid leukemia. Clin Lymphoma Myeloma Leuk. 2011; 11: S60-64.

2. Biggs JC, Horowitz MM, Gale RP, Ash RC, Atkinson K, Helbig W, et al. Bone marrow transplants may cure patients with acute leukemia never achieving remission with chemotherapy. Blood. 1992; 80: 1090-1093.

3. Fung HC, Stein A, Slovak MI, O'Donnell MR, Snyder DS, Cohen S, et al. A long-term follow-up report on allogeneic stem cell transplantation for patients with primary refractory acute myelogenous leukemia: impact of cytogenetic characteristics on transplantation outcome. Biol Blood Marrow Transplant. 2003; 9: 766-771.

4. Bross PF, Beitz J, Chen G, Chen XH, Duffy E, Kieffer L, et al. Approval summary: gemtuzumabozogamicin in relapsed acute myeloid leukemia. Clin Cancer Res. 2001; 7: 1490-1496.

5. Rowe JM, Tallman MS. How I treat acute myeloid leukemia. Blood. 2010; 116: 3147-3156.

6. Gandhi V, Estey E, Du M, Nowak B, Keating MJ, Plunkett W. Modulation of the cellular metabolism of cytarabine and fludarabine by granulocytecolony-stimulating factor during therapy of acute myelogenous leukemia. Clin Cancer Res. 1995; 1: 169-178.

7. Estey E, Plunkett W, Gandhi V, Rios MB, Kantarjian H, Keating MJ. Fludarabine and arabinosylcytosine therapy of refractory and relapsed acute myelogenous leukemia. Leuk Lymphoma. 1993; 9: 343-350.

8. Jabbour E, Garcia-Manero G, Cortes J, Ravandi F, Plunkett W, Gandhi V, et al. Twice-daily fludarabine and cytarabine combination with or without gentuzumab ozogamicin is effective in patients with relapsed/refractory acute myeloid leukemia, high-risk myelodysplastic syndrome, and blast- phase chronic myeloid leukemia. Clin Lymphoma Myeloma Leuk. 2012; 12: 244251.

9. Giles F, Estey E, O'Brien S. Gemtuzumab ozogamicin in the treatment of acute myeloid leukemia. Cancer. 2003; 98: 2095-2104.

10. Sievers EL. Efficacy and safety of gemtuzumab ozogamicin in patients with CD33-positive acute myeloid leukaemia in first relapse. Expert Opin Biol Ther. 2001; 1: 893-901.

11. Oken MM, Creech RH, Tormey DC, Horton J, Davis TE, McFadden ET, et al. Toxicity and response criteria of the Eastern Cooperative Oncology Group. Am J Clin Oncol. 1982; 5: 649-655.

12. Chomczynski $P$, Sacchi N. Single-step method of RNA isolation by acid guanidinium thiocyanate-phenol-chloroform extraction. Anal Biochem. 1987; 162: 156-159.

13. van Dongen JJ, Macintyre EA, Gabert JA, Delabesse E, Rossi V, Saglio $G$, et al. Standardized RT-PCR analysis of fusion gene transcripts from chromosome aberrations in acute leukemia for detection of minimal residual disease. Report of the BIOMED-1 Concerted Action: investigation of minimal residual disease in acute leukemia. Leukemia. 1999; 13: 1901-1928.

14. Thiede C, Steudel C, Mohr B, Schaich M, Schäkel U, Platzbecker U, et al. Analysis of FLT3-activating mutations in 979 patients with acute myelogenous leukemia: association with FAB subtypes and identification of subgroups with poor prognosis. Blood. 2002; 99: 4326-4335. 
15. Noguera NI, Ammatuna E, Zangrilli D, Lavorgna S, Divona M, Buccisano F et al. Simultaneous detection of NPM1 and FLT3-ITD mutations by capillary electrophoresis in acute myeloid leukemia. Leukemia. 2005; 19: 1479-1482.

16. Gorello P, Cazzaniga G, Alberti F, Dell'Oro MG, Gottardi E, Specchia G, et al. Quantitative assessment of minimal residual disease in acute myeloid leukemia carrying nucleophosmin (NPM1) gene mutations. Leukemia. 2006; 6: 1103-1118.

17. Ottone T, Zaza S, Divona M, Hasan SK, Lavorgna S, Laterza S, et al Identification of emerging FLT3 ITD-positive clones during clinical remission and kinetics of disease relapse in acute myeloid leukaemia with mutated nucleophosmin. Br J Haematol. 2013; 161: 533-540.

18. Mitelman F. An International System for Human Cytogenetic Nomenclature. Karger. Basel: 1995; 1-111.

19. Venditti A, Buccisano F, Del Poeta G, Maurillo L, Tamburini A, Cox C, et al. Level of minimal residual disease after consolidation therapy predicts outcome in acute myeloid leukemia. Blood. 2000; 96: 3948-3952.

20. Treleaven J, Gennery A, Marsh J, Norfolk D, Page L, Parker A, et al Guidelines on the use of irradiated blood components prepared by the British Committee for Standards in Haematology blood transfusion task force. $\mathrm{Br} \mathrm{J}$ Haematol. 2011; 152: 35-51.

21. Cheson BD, Bennett JM, Kopecky KJ, Büchner T, Willman CL, Estey EH, et al. International Working Group for Diagnosis, Standardization of Response Criteria, Treatment Outcomes, and Reporting Standards for Therapeutic Trials in Acute Myeloid Leukemia. Revised recommendations of the International Working Group for Diagnosis, Standardization of Response Criteria, Treatment Outcomes, and Reporting Standards for Therapeutic Trials in Acute Myeloid Leukemia. J ClinOncol. 2004; 22: 576

22. Common Terminology Criteria for Adverse Events (CTCAE). 2009; USA Department of Health And Human Services.

23. Grimwade D, Walker H, Oliver F, Wheatley K, Harrison C, Harrison G, et al. The importance of diagnostic cytogenetics on outcome in AML: analysis of 1,612 patients entered into the MRC AML 10 trial. The Medical Research Council Adult and Children's Leukaemia Working Parties. Blood. 1998; 92 : 2322-2333.

24. Martin MG, Augustin KM, Uy GL, Welch JS, Hladnik L, Goyal S, et al Salvage therapy for acute myeloid leukemia with fludarabine, cytarabine, and idarubicin with or without gemtuzumab ozogamicin and with concurrent or sequential G-CSF. Am J Hematol. 2009; 84: 733-737.

25. Kantarjian H, Gandhi V, Cortes J, Verstovsek S, Du M, Garcia-Manero G, et al. Phase 2 clinical and pharmacologic study of clofarabine in patients with refractory or relapsed acute leukemia. Blood. 2003; 102: 2379-2386.

26. Bergua JM, Montesinos $P$, Martinez-Cuadrón D, Fernández-Abellán $P$, Serrano J, Sayas MJ, et al. A prognostic model for survival after salvage treatment with FLAG-Ida +/- gemtuzumab-ozogamicine in adult patients with refractory/relapsed acute myeloid leukaemia. $\mathrm{Br}$ J Haematol. 2016; 174: 700710.

27. Breems DA, Van Putten WL, Huijgens PC, Ossenkoppele GJ, Verhoef GE Verdonck LF, et al. Prognostic index for adult patients with acute myeloid leukemia in first relapse. J Clin Oncol. 2005; 23: 1969-1978.

28. Walter RB, Raden BW, Kamikura DM, Cooper JA, Bernstein ID. Influence of CD33 expression levels and ITIM dependent internalization on gemtuzumabozogamicin-induced cytotoxicity. Blood. 2005; 105: 1295-1302.

29. Amadori S, Suciu S, Stasi R, Willemze R, Mandelli F, Selleslag D, et al. Gemtuzumabozogamicin $\left(\right.$ Mylotarg $^{\circledR}$ ) as single-agent for frail patients 61 years of age and older with acute myeloid leukemia: final results of AML-15B a phase 2 study of the European Organisation for Research and Treatment of Cancer and GruppoltalianoMalattieEmatologichedell'Adulto Leukemia Groups. Leukemia. 2005; 19: 1768-1773.
30. Burnett AK, Hills RK, Milligan D, Kjeldsen L, Kell J, Russell NH, et al. Identification of patients with acute myeloblastic leukemia who benefit from the addition of gemtuzumabozogamicin: results of the MRC AML15 trial. J Clin Oncol. 2011; 29: 369-377.

31. Castaigne S, Pautas C, Terré C, Raffoux E, Bordessoule D, Bastie JN, et al. Effect of gemtuzumab ozogamicin on survival of adult patients with de-novo acute myeloid leukaemia (ALFA-0701): a randomised, open-label, phase 3 study. Lancet. 2012; 379: 1508-1516.

32. Capria S, Trisolini SM, Minotti C, Stefanizzi C, Cardarelli L, Cartoni C, et al. Ara-C, Idarubicine and GentuzumabOzogamicin (AIM) as Salvage Treatment in Advanced Acute Myeloid Leukemia Patients. Mediterr J Hematol Infect Dis. 2012; 4: e2012072.

33. Loke J, Khan JN, Wilson JS, Craddock C, Wheatley K. Mylotarg has potent anti-leukaemic effect: a systematic review and meta-analysis of anti-CD33 antibody treatment in acute myeloid leukaemia. Ann Hematol. 2015; 94: 361373.

34. Amadori S, Suciu S, Stasi R, Salih HR, Selleslag D, Muus P, et al. Sequential combination of gemtuzumabozogamicin and standard chemotherapy in older patients with newly diagnosed acute myeloid leukemia: results of a randomized phase III trial by the EORTC and GIMEMA consortium (AML-17). J ClinOncol. 2013; 31: 4424-4430

35. Petersdorf SH, Kopecky KJ, Slovak M, Willman C, Nevill T, Brandwein J, et al. A phase III study of gemtuzumabozogamicin during induction and post-consolidation therapy in younger patients with acute myeloid leukemia. Blood. 2013; 121: 4854-4860

36. Delaunay J, Recher C, Pigneux A. Addition of gemtuzumabozogamycin to chemotherapy improves event-free survival but not overall survival of AML patients with intermediate cytogenetics not eligible for allogeneic transplantation. Results of the GOELAMS AML 2006 IR Study. ASH Annual Meet Abstr. 2011; 118.

37. Burnett A, Cavenagh J, Russell N, Hills R, Kell J, Jones G, et al. Defining the dose of gemtuzumabozogamicin in combination with induction chemotherapy in acute myeloid leukemia:a comparison of $3 \mathrm{mg} / \mathrm{m} 2$ with $6 \mathrm{mg} / \mathrm{m} 2$ in the NCRI AML17 trial. Haematologica. 2016; 101: 724-731.

38. Chantepie SP, Reboursiere E, Mear JB, Gac AC, Salaun V, Benabed K, et al. Gemtuzumab ozogamicin in combination with intensive chemotherapy in relapsed or refractory acute myeloid leukemia. Leuk Lymphoma. 2015; 56: 2326-2330.

39. Litzow MR, Othus M, Cripe LD, Gore SD, Lazarus HM, Lee SJ, et al. Failure of three novel regimens to improve outcome for patients with relapsed or refractory acute myeloid leukaemia: a report from the Eastern Cooperative Oncology Group. Br J Haematol. 2010; 148: 217-225.

40. Forman SJ, Rowe JM. The myth of the second remission of acute leukemia in the adult. Blood. 2013; 121: 1077-1082.

41. Cornelissen JJ, van Putten WL, Verdonck LF, Theobald M, Jacky E, Daenen $\mathrm{SM}$, et al. Results of a HOVON/SAKK donor versus no-donor analysis of myeloablative HLA-identical sibling stem cell transplantation in first remission acute myeloid leukemia in young and middle-aged adults: benefits for whom? Blood. 2007; 109: 3658-3666.

42. Ravandi F, Ritchie EK, Sayar H, Lancet JE, Craig MD, Vey N, et al. Vosaroxin plus cytarabine versus placebo plus cytarabine in patients with first relapsed or refractory acute myeloid leukaemia (VALOR): a randomised, controlled, double-blind, multinational, phase 3 study. Lancet Oncol. 2015; 16: 10251036.
Ann Hematol Oncol - Volume 4 Issue 4 - 2017

ISSN : 2375-7965 | www.austinpublishinggroup.com

Del Principe et al. (C) All rights are reserved
Citation: Cefalo M, Del Principe Ml, Buccisano F, Di Piazza F, Ottaviani L, Maurillo L, et al. Fludarabine, Cytarabine and Gentuzumab Ozogamicin (FLA-GO) as Salvage Therapy and Bridge to Transplant in Adult Relapsed Acute Myeloid Leukemia (AML) Patients. Ann Hematol Oncol. 2017; 4(4): 1145. 